\title{
The effect of relationship enhancement approach training on job stress and quality of marital relationship among municipality staffs
}

\author{
Dargahi Sh, PhD Student ${ }^{1}$, Rezaiee Ahvanuiee M, $\mathrm{MSc}^{2}$, Ghasemi Jobaneh R, PhD Student ${ }^{3}$, \\ Khorasani $\mathrm{AH}, \mathrm{PhD}^{4 *}$ \\ 1- PhD Student in Counseling, Faculty of Education Science and Psychology, University of Mohaghegh Ardabili, Ardabil, \\ Iran. 2- MSc in Counseling, Dept. of Counseling, Faculty of Psychology and Education Science, Kharazmi University, \\ Tehran, Iran. 3- PhD Student in Counseling, Shahid Chamran University of Ahvaz, Ahvaz, Iran. 4- PhD in Psychology, \\ Head of the Counseling Center, Damghan University, Damghan, Iran.
}

\begin{abstract}
Received: September 2017, Accepted: October 2017

Background: Staffs may suffer from high job stress and low quality of the marital relationship. Constructive skills can have a positive impact on them. Thus, the aim of the current research was to investigate the effectiveness of relationship enhancement (RE) approach training on job stress and quality of marital relationship among staffs of the Municipality of Karaj, Iran.

Materials and Methods: The research method was semi-experimental and the pretest- posttest design with the control group was used. Population in this study consisted of Municipal staffs of Karaj in 2015. Samples were selected at first by available sampling method. After completing job stress and marital status questionnaires, samples were assigned using the random split method in two experimental and control groups (15 ones per group). The experimental group participated in 7 sessions of group training based on RE approach and control group received no intervention. The gathered data were analyzed by SPSS software.

Results: There was a significant difference between the posttest scores of the experimental and control groups. Moreover, $\mathrm{RE}$ approach training could significantly reduce job stress $(\mathrm{P}=0.01, \mathrm{~F}=$ $6.19)$ and increase quality of marital relationship $(\mathrm{P}<0.01, \mathrm{~F}=7.79)$.

Conclusions: According to the effectiveness of RE approach in reducing job stress and increasing quality of marital relationship, it is recommended that this program is used in private and public centers to increase the health of the staff.
\end{abstract}

Keywords: Job Stress, Marital Relationship, Training

\section{Introduction}

Regardless of financial income, job provides basic needs of a human such as physical and mental practice, social connection or relationship, self-worth, confidence, and competence (1). Meanwhile, job can also be a fundamental source of stress (2). Job stress, at a moderate level, exists as a part of every human life, but it can become a source of failure and cognitive-behavioral disorders if it gets chronic and constant (3-5). Job stress is related to various negative consequences. Accordingly, research results have indicated that there is a significant relationship between job stress and job dissatisfaction (6), depression (7), anxiety (8), and mental disorders (9). Job stress is one of the most important stresses with an external origin that can indirectly exert a negative effect on marital quality $(10,11)$. In other words, when responsibilities, concerns, and pressures from job or family fields infiltrate into the other field, the balance between these two fields would be disturbed (12). In fact, there is a Mutual relationship between work and family

* Corresponding author: Amir Hamzeh Khorasani, Head of the Counseling Center, Damghan University, Damghan, Iran.

E-mail: khorasani.dubs@gmail.com 
and the tension experienced by the person at work can affect his or her family relationships and vice versa (13-15). Research results in these area have suggested that job-family conflict is related to a wide range of negative consequences such as low levels of well-being $(16,17)$, marital satisfaction (18), enjoying the moments of life (19), emotional tensions with depression symptoms (20), family satisfaction (21), workload and burnout (22), organizational commitment (23).

One of the programs that affects the family and professional problems of employees is the enrichment program (24). Relationshipassociated problems are accompanied by negative consequences such as loneliness and reduced quality in family relationships, career relationships, and relationships with friends. Therefore, psychologists and particularly family therapists have proposed the relationship enhancement (RE) program for improving interpersonal relationships, reducing interpersonal conflicts and improving their relationships. RE is an approach which integrates psychoanalytic, behavioral, interpersonal, and humanistic approaches. The purpose of enhancement in the job-family area is to increase the individuals' life in one role through the experience they have gained in the other role. In this approach, job can enhance family- and career-life (25). Various reports have shown the effectiveness of the RE program on increasing couple intimacy (25), increasing life satisfaction $(26,27)$, improving marital quality (28), enhancing life quality (29), increasing psychological adjustment (30, $31)$, and commitment and trust $(32,33)$.

Although most of the above-mentioned evidence indicate the direct effectiveness of the relationship enhancement program on marital relationship, the existing gap in researches conducted in the field of job-family enhancement and the importance of the relationship enhancement program in solving job conflicts and increasing emotional relationships has led the researchers to investigate the effectiveness of the $\mathrm{RE}$ program on job stress and marital quality.

\section{Material and Methods}

The present research is an applied research which was conducted by an experimental method with a pretest-posttest with control group design. The statistical population in this study was the married staff of the Municipality of Karaj, Iran, in the spring of 2015. After receiving the introduction letter for Municipality and the agreement of the educational department of this center, the present research was introduced to the municipality staff. The inclusion criteria for the current research were as follows: the education level of diploma (at least), being married and having at least one child. Among 85 qualified individuals enrolled for participation in the research, 30 individuals were selected through simple random sampling method (by a sortation method) to participate in the research in the frame of inservice courses. Finally, they were assigned to two experiment and control groups (15 per group). In this study, the following questionnaires were used for collecting the data:

Job stress inventory: This inventory was developed by Spielberger and includes 30 items. The respondents rate each item according to the intensity of stress they would create from one to nine. The minimum score is 30 and the maximum score obtained in this inventory is 270 . In Iran, a research conducted by Esfandyari et al. showed the reliability of 0.84 by Cronbach's alpha coefficient (34).

Golombok Rust Inventory of Marital Status (GRIMS): The GRIMS inventory (35) includes 28 statements with 4 options for the answers: completely disagree, disagree, agree and completely agree. The respondents choose one of the 4 options according to their marital status. The minimum score is 0 and the maximum score is 84 . A high score indicates a poor marital status. This inventory has been developed by Rust et al. which is used for evaluating the quality of the marital relationship. This inventory shows the individuals' overall assessment of their life. In 
a research in Iran, the reliability was reported to be 0.91 for women and 0.89 for men through Cronbach's alpha coefficient which indicates the authenticity of this inventory for Iranian culture (36).

After random assignment of the individuals in two groups, and according to the score of mean \pm standard deviation (SD) of the dependent variables in the pretest, the experiment group received the RE program and the control group was put in the waiting list and received no intervention. It was explained to the participants that the training sessions were designed for two purposes: first, to help them improve their relationships in work and family fields, and second, for conducting a research. After completing the questionnaires as the pretest by both groups, the experiment group received seven 90- minute training sessions of RE program. The control group received no intervention in this step, but for the ethical issues related to the research, another course was held for the control group after finishing the research. It should be noted that this training course lasted from early May to early July of 2015. In terms of ethical considerations, the confidentiality of the information was explained and a written consent was taken from the participants. Furthermore, the current research owns an ethical code from Kharazmi University of Tehran, Iran.

The protocol for RE training sessions (28) in the present research is listed in table 1 . The obtained data were analyzed by SPSS software (version 19, SPSS Inc., Chicago, IL, USA) using univariate analysis of covariance (ANCOVA) in the significance level of 0.05 .

Table 1: The protocol for relationship enhancement (RE) training sessions

\begin{tabular}{cl}
\hline Session & \multicolumn{1}{c}{ Aim } \\
\hline 1 & $\begin{array}{l}\text { Conducting the pretest, getting familiar with the group administrator, introducing the group } \\
\text { members, explaining the rules and determining the frameworks, and describing general principles } \\
\text { of relational enhancement skills with assigning the task }\end{array}$ \\
\hline 2 & $\begin{array}{l}\text { Helping the individuals to deepen their empathetic mutual understanding skill and have an } \\
\text { emotional bond in their dialogue. They also had to improve the empathy skill in their connections } \\
\text { and appreciate what others do. A task is also assigned to the group. }\end{array}$ \\
\hline 3 & $\begin{array}{l}\text { Helping the individuals to improve the cooperation spirit by their discussion/negotiation skill in } \\
\text { order to facilitate an open relationship, and finally enhance their collaborative problem-solving } \\
\text { skill. Also, they must express themselves in a way that minimizes the defensive posture of the } \\
\text { other person, along with a task. }\end{array}$ \\
4 & $\begin{array}{l}\text { Helping the individuals to improve their ability to control emotions and manage the conflict } \\
\text { condition in a more effective way so that security and respect would be maintained in their } \\
\text { relationships, along with a task }\end{array}$ \\
\hline 5 & $\begin{array}{l}\text { By problem/conflict-solving skill in creating a solution, agreement or an action plan, the } \\
\text { individuals are helped to learn an approach which increases the possibility of gaining a satisfactory } \\
\text { result for both sides, along with task }\end{array}$ \\
\hline 6 & $\begin{array}{l}\text { Through the skill of changing behavior (of oneself) and helping others to change, the individuals } \\
\text { are helped to increase the possibility of successful execution of a consensus change in their } \\
\text { behavior. Also, by using facilitation skill, keep their dialogues in an appropriate direction and } \\
\text { monitor (control) their dialogues. A task is also given. }\end{array}$ \\
\hline $\begin{array}{l}\text { The individuals are helped to stabilize the place of these skills in their life by generalization skill, } \\
\text { and enhance these skills in long-term by using maintenance skill. Finally, summarization and } \\
\text { posttest would be done }\end{array}$ \\
\hline
\end{tabular}

\section{Results}

Mean \pm SD of age in the experiment group was $36.00 \pm 5.13$, while it was $35.53 \pm 5.80$ for the control group. According to results of table 2 , it was observed that there was no significant difference between the scores of experiment and control groups in the pretest phase, while the reduction in scores of job stress and increase in scores of marital quality in the posttest phase were more in the experiment group compared to the control group. 
Table 2: Frequency distribution of demographic characteristics of subjects in two groups

\begin{tabular}{ccccc}
\hline Demographic characteristics & Experimental group & Control group & \multirow{2}{*}{$\mathbf{P}^{*}$} \\
\hline \multirow{3}{*}{ Education } & Diploma & $6(40)$ & $6(40)$ & \multirow{2}{*}{0.071} \\
\cline { 2 - 4 } Age & Bachelor & $6(40)$ & $5(34)$ & \\
\cline { 2 - 4 } & Employed & $3(20)$ & $4(26)$ & \\
\cline { 2 - 4 } & $20-25$ & $4(26)$ & $4(26)$ & \\
\cline { 2 - 4 } & $25-30$ & $6(40)$ & $5(34)$ & \\
\cline { 2 - 4 } Economic status & $30-40$ & $5(34)$ & $6(40)$ & \\
\cline { 2 - 4 } & Low & $3(20)$ & $8(26)$ & \\
\cline { 2 - 4 } & Moderate & $8(54)$ & $3(20)$ &
\end{tabular}

Data are shown as number $(\%),{ }^{*}$ Chi-square test

The Kolmogorov-Smirnov test was used to investigate the normality of the scores distribution. The results indicated that the assumption of normality in data distribution was established in both phases of job stress and marital quality $(\mathrm{P}>0.05)$. The Levene's test also showed that the $\mathrm{F}$ value seen in the 0.05 significance level was not significant $(\mathrm{P}>$
0.05); therefore, the variance of job stress and marital quality between the participants (experiment and control groups) was not different and the variances were equal. The univariate ANCOVA was used for examining the effectiveness of the RE program and the results are shown in tables 3 and 4 .

Table 3: Mean and standard deviation (SD) of the scores of pretest and posttest research variables in married staff of the Municipality of Karaj, Iran, in 2015

\begin{tabular}{ccccc}
\hline \multirow{2}{*}{ Variable } & \multicolumn{2}{c}{ Experiment } & \multicolumn{2}{c}{ Control } \\
\cline { 2 - 5 } & Pretest & Posttest & Pretest & Posttest \\
\hline Job stress & $106.07 \pm 25.56$ & $91.47 \pm 15.57$ & $99.40 \pm 17.85$ & $96.73 \pm 14.79$ \\
\hline Marital quality & $38.40 \pm 2.23$ & $46.40 \pm 7.37$ & $40.47 \pm 3.73$ & $39.53 \pm 5.08$ \\
\hline
\end{tabular}

Data are shown as mean \pm standard deviation $(\mathrm{SD})$

As observed in table 4, the difference between mean scores of job stress in the posttest after controlling for scores of pretest in both groups was significant. It was shown that RE training reduced job stress $(\mathrm{P}=0.01, \mathrm{~F}=6.19)$. Also, ANCOVA results displayed $18 \%$ of effect size.
As can be seen in table 5, the difference between mean scores of marital quality in the posttest after controlling for scores of pretest in both groups was significant. It means that $\mathrm{RE}$ training led to increase in marital quality $(\mathrm{P}<0.01, \mathrm{~F}=7.79)$. Also, results of ANCOVA test showed $22 \%$ of effect size.

Table 4: Univariate analysis of covariance (ANCOVA) for job stress of married staff of the Municipality of Karaj, Iran, in 2015

\begin{tabular}{ccccccc}
\hline $\begin{array}{c}\text { Source of } \\
\text { variation }\end{array}$ & $\begin{array}{c}\text { Sum of } \\
\text { squares }\end{array}$ & $\begin{array}{c}\text { Degree of } \\
\text { freedom }\end{array}$ & $\begin{array}{c}\text { Mean of } \\
\text { squares }\end{array}$ & F & Significance & Effect size \\
\hline Pretest & 3955.20 & 1 & 3955.20 & 42.62 & 0.01 & 0.61 \\
\hline Group & 574.67 & 1 & 574.67 & 6.19 & 0.01 & 0.18 \\
\hline Error & 2505.46 & 27 & 92.79 & - & - & - \\
\hline Total & 272313 & 30 & - & - & - & - \\
\hline
\end{tabular}


Table 5: Univariate analysis of covariance (ANCOVA) for marital quality of married staff of the Municipality of Karaj, Iran, in 2015

\begin{tabular}{ccccccc}
\hline $\begin{array}{c}\text { Source of } \\
\text { variation }\end{array}$ & $\begin{array}{c}\text { Sum of } \\
\text { squares }\end{array}$ & $\begin{array}{c}\text { Degree of } \\
\text { freedom }\end{array}$ & $\begin{array}{c}\text { Mean of } \\
\text { squares }\end{array}$ & F & Significance & Effect size \\
\hline Pretest & 0.53 & 1 & 0.53 & 0.01 & 0.91 & 0.10 \\
\hline Group & 324.09 & 1 & 324.09 & 7.79 & 0.01 & 0.22 \\
\hline Error & 1122.80 & 27 & 41.58 & - & - & - \\
\hline Total & 56861 & 30 & - & - & - & - \\
\hline
\end{tabular}

\section{Discussion}

The present research was conducted with the aim of investigating the effectiveness of RE approach on job stress and marital quality among the staff of Municipality. Accordingly, results of the present research suggested that training of RE approach can be effective in reducing job stress and increasing marital stress $(\mathrm{P}<0.01)$. These results can be partly consistent with other studies which have considered the effectiveness of RE approach on quality of life and marital intimacy (22-24). Also, findings of the current research are consistent with results of the research of Rezaiee Ahvanuiee which indicated that training of RE approach is effective on careerfamily conflict (37).

Researchers have attributed the high effectiveness of RE approach to different factors such as increasing psychologicalemotional satisfaction in close relationships and reducing conflict and struggles (38). In fact, establishing and maintaining a healthy and satisfactory marital relationship requires a number of conditions. Providing an intimate atmosphere among couples, optimism, equality, flexibility, sense of agency and awareness, commitment and loyalty, equity and peaceful resolving of problems are among the characteristics of a healthy and effective relationship in a family which is a necessary requirement for stabilizing marital relationships and, therefore, having a satisfactory life.

On the other hand, research reports have shown that conflict, as the main source of stress, leads to harmful consequences for the physical and mental health of employed individuals, such as poor performance in parental-marital tasks, moodiness, reduced life satisfaction, and low mental health (39). Other evidence suggests that job-role stress decreases life satisfaction (40). The RE approach for appropriate comping against stressful conditions, especially in job environments, helps individuals to become less distressed and possess higher resilience in face of problems, and therefore, their mental health is improved which is among basic inhibitors and protectors against job stress (41). RE seeks to satisfy the mutual needs in the relationship and also tries to create a desirable status through understanding personal-practical differences and similarities. In RE program, individuals first try to find a personal identity and satisfy mutual needs in the relationship, and they try to consider these needs and purposes as the aim of forming the relationship. Then, by teaching skills such as empathy, discussion and negotiation, conflict management, and solving issue/conflict, individuals learn that they must try to form the relationship in line with improving and enhancing interpersonal relationships which are truly a fundamental basis for conflictsolving (28).

The present research was conducted for the staff of Municipality of Karaj in 2015, and we should be cautious in generalizing the findings to other statistical populations. According to the effectiveness of the RE program on solving the job-family conflict in the present research, it is recommended that $\mathrm{RE}$ training would be used for solving conflict among all the staff in order to reduce job stress and improve marital quality among these individuals. Furthermore, it is recommended that the association between the duration of relationship enhancement 
training and its effectiveness in solving jobfamily stress would be investigated in future research.

\section{Conclusion}

Findings of the present research showed the importance of training based RE in reducing job stress and increasing marital quality. Therefore, in educational programs conducted for increasing performance among staff, the important role of the family should be noted along with the job. Moreover, in addition to conducting certain programs for improving quality of job life among the staff, improvement of their family function should also be considered.

\section{Acknowledgements}

We appreciate the cooperation of the staff and authorities of Municipality of Karaj in the present research.

Conflict of interest: None declared

\section{References}

1- Spector PE, Allen, TD, Poelmans SAY,Lapierre LM, Cooper CL, Michael O, et al. Cross-national differences in relationships of work demands, job, satisfaction, and turnover intentions with work-family conflict. Pers Psychol 2007; 60(4):805-35

2- Mohammadi Sh, Maghsodi M. An investigation of the relationship between jobs stress and marital satisfaction among females personnel. Quarterly Journal of Career \& Organizational Counseling 3(9):74-87.

3- Lu Ch-S, Kuo S-Y. The effect of job stress on self-reported safety behavior in container terminal operations: The moderating role of emotional intelligence. Transp Res Part F Traffic Psychol Behav 2016; 37:10-26.

4- Gadzella BM. Confirmatory factor analysis and internal consistency of student-life stress inventory. Journal of Instructional Psychology 2004; 28(2):84-94.

5- Yao SQ, Tain L, Pang BD, Bai YP, Fan XY, Shen FH, et al. Investigation on job stress of pediatricians and nurses working in pediatric department. Zhonghua Lao Dong Wei Sheng Zhi Ye Bing Za Zhi 2008; 26(9):529-32.

6- Lee M, Larson R. The Korean 'examination hell': Long hours of studying, distress,and depression. J Youth Adolesc 2000; 29(2):249-71.

7- Ang RP, Huan VS. Academic expectations stress inventory: development, factory analysis, reliability, and validity. Educ Psychol Meas 2006; 66(3):522-39.

8- Murry SL, Rose P, Bellavia GM, Holmes JG, Kusche AG. When rejection stings: how self-esteem constraints relationshipenhancement processes. J Pers Soc Psychol 2002; 83(3): 556-73.

9- Wang W, Kong AW, Chair SY. Relationship between job stress level \& coping strategies used by Hong Kong nurses working in an acute surgical unit. Appl Nurs Res 2011; 24(4):38-43.

10- Bhattacherjee Sh, Ray K, Roy J.K, Mukherjee A, Roy H, Datta S. Job satisfaction among doctors of a government medical college and hospital of eastern India. Nepal J Epidemiol 2016; 6(3):596-602.

11- Ghasemi SR, RajabiGilan N, Reshadat S, Ahmadian M. The relationship between job satisfaction and health-related quality of life in the teachers at Gilan-e-Gharb city in 2013. Journal of Rafsenjan University of Medical Sciences 2014; 13(1):13-26.

12- Hall ME, Anderson TL, Willingham MM. Diapers, dissertations, and other holy things: The experiences of mothers working in Christion colleges and universities. Christion Higher Education 2004; 3(1):41-60.

13- Greenhaus JH, Beutell NJ. Sources of conflict between work and family roles. Acad Manage Rev 1985; 10(1):76-88.

14- Raymo JM, Sweeny MM. Work-family conflict and retirement preferences. The Journal of Gerontology: Series B 2006; 61(3):S161-9.

15- Gurbuz S, Turunce O, Celik M. The impact of perceived organizational support on work-family conflict: Does role overload have a mediating role? Economic and Industrial Democracy 2013; 34(1):145-60.

16- Burke RJ, Greenglass ER. Hospital restructuring stressors, work-family concerns and psychological well-being among nursing staff. Community Work Fam 2001; 4(1):49-62.

17- Andrade C, Mikula G. Work-family conflict and perceived justice as mediators 
of outcomes of women's multiple workload. Marriage Fam Rev 2014; 50(3): 285-306.

18- Vil NMSt. African American marital satisfaction as a function of work-family balance and work-family conflict and implications for social workers. J Hum Behav Soc Environ 2014; 24(2):208-16.

19- Camgoz SM. The role of savoring in work-family conflict. Soc Behav Pers 2014; 42(2):177-88.

20- Killien MG, Habermann B, Jarrett M. Influence of employment characteristics on postpartum mothers' health. Women Health 2001; 33(1-2):63-81.

21- Boyar SL, Mosley Jr DC. The relationship between core self-evaluations and work and family satisfaction: The moderating role of work-family conflict and facilitation. J Vocat Behav 2007; 71(2):265-81.

22- Beshlideh K, Darvishi, M, Koraei A. A study of the relationship between interpersonal conflict and workload with burnout in female nurses of educational hospitals of Ahwaz: the mediating role of work-family conflict. Journal of Family Counseling \& Psychotherapy 2012; 2.1(Special Issue- Family and Divorce):16-27.

23- Wayne JH, Casper WJ, Matthews RA, Allen TD. Family-supportive organization perceptions and organizational commitment: The mediating role of workfamily conflict and enrichment and partner attitudes. J Appl Psychol 2013; 98(4):60622.

24- Aycan Z, Eskin M. Relative contributions of childcare, spousal support and organizational support in reducing workfamily conflict for men and women: The case of turkey. Sex Roles 2005; 53(78):453-71.

25- Ebrahimi P, Sanai Zaker B, Nazari AM. Assessment of the effectiveness of training relationship enhancement approach on increasing intimacy in dual-career couples. Scientific Journal of Kurdistan University of Medical Sciences 2012; 16(4):37-42.

26- Accordino MP, Guerney Jr BG. Relationship enhancement couples and family outcome research of the last 20 years. Fam J 2003; 11(2): 162-6.

27- Oaliyaa $\mathrm{N}$, faatehee $\mathrm{M}$, Bahraamee $\mathrm{F}$. Increasing marital satisfaction through an enrichment program. Quarterly Journal of New Thoughts on Education 2008; 4(1):930.
28- Nazari AM. Surveying and comparison of the effectiveness of relationship enhancement approach and solution focused counseling on marital satisfaction of Dual-careercouples. [PhD thesis]. Tahran: Kharazmi University of Tehran; 2005

29- Isanejad O, Ahmadi A, Etemadi O. Effectiveness of relationship enhancement on marital quality of couples. International Journal of Behavioral Science 2010; 4(1):9-16

30- Blanchard VL, Hawkins AJ, Baldwin SA, Fawcett EB. Investigating the effects of marriage and relationship education on couples' communication skills: a metaanalytic study. J Fam Psychol 2009; 23(2):203-14.

31- Kalkan M, Ersanli E. The effect of the marriage enrichment program based on cognitive- behavioral approach on the marital adjustment of couples. Educational Sciences: Theory \& Practice 2008; 8(3):977-86.

32- Brooks LW, Guerney Jr B, Mazza N. Relationship enhancement couples group therapy. J Fam Soc Work 2002; 6(2):2542.

33- Markman HJ, Rhoades GK. Relationship education research: current status and future directions. J Marital Fam Ther 2012; 38(1):169-200.

34- Jafari A, Amiri Majd M, Esfandiary Z. Relationship between personality characteristics and coping strategies with job stress in nurses. Quarterly Journal of Nursing Management 2013; 1(4):36-44.

35- Rust J, Bennun I, Crowe M, Golombok S. The golombok rust inventory of marital state (GRIMS). Sex Relation Ther 2010; 25(1):48-53.

36- Besharat MA, Ganji P. The moderating role of attachment styles on the relationship of alexithymia with marital satisfaction. Journal of Fundamentals of Mental Health 2013; 14(56):324- 35.

37- Rezaei Ahvanuiee M. Surveying the effectiveness of relationship enhancement approach on work- family conflict [MSc thesis]. Tehran: Kharazmi University of Tehran; 2015.

38- Ronan GF, Dreer LW, Dollard KM, Ronan DW. Violent couples: coping and communication skills. J Fam Violence 2004; 19(2):131-7.

39- Addae HM, Wang X. Stress at work: linear and curvilinear effects of psychological-, job-, and organization- 
related factors: an exploratory study of trinidad and tobage. Int J Stress Manage 2006; 13(4):476-93.

40- Bedeiean AG, Bruke BG, Moffett RG. Outcomes of work-family conflict among married male and female professionals. $\mathbf{J}$ Manage 1998; 14(3):475-91.
41- Shahraki Vahed A, Hamuleh MM. Sanchuli J, Hamedi Shahraki S. Assessment of the relationship between mental health and job stress among nurses. Pars Journal of Medical Sciences 2010; 8(3):34-40. 